\title{
Evaluating age in Octopus vulgaris: estimation, validation and seasonal differences
}

\author{
Ester Canali ${ }^{1}$, Giovanna Ponte ${ }^{1, *}$, Paola Belcari ${ }^{2,3}$, Francisco Rocha ${ }^{4}$, \\ Graziano Fiorito $^{1}$ \\ ${ }^{1}$ Stazione Zoologica Anton Dohrn, Villa Comunale, 80121 Napoli, Italy \\ ${ }^{2}$ Dipartimento di Scienze dell'Uomo e dell'Ambiente, University of Pisa, 56126 Pisa, Italy \\ ${ }^{3}$ London Centre for Nanotechnology and Department of Physics and Astronomy, University College London, London, UK \\ ${ }^{4}$ Department of Ecology and Animal Biology, University of Vigo, Campus of Lagoas-Marcosende, 36310 Vigo, Spain
}

\begin{abstract}
Several internal structures have been used to estimate age in the cephalopod Octopus vulgaris, but with limited accuracy. We estimated age by investigating growth increments (rings) in the upper beaks of octopus collected between 2003 and 2010 in the Bay of Naples, Italy (Mediterranean Sea). To validate the daily periodicity of ring deposition, 'thermal shock marking' was for the first time applied to live octopuses fished between 2009 and 2010; this method produced a mark on the beak corresponding to the day of thermal shock, enabling us to elucidate the relationship between ring number and time elapsed (i.e. $~ 30 \mathrm{~d}$ ). In addition, rings were counted in $>700$ preserved specimens of $O$. vulgaris collected between 2003 and 2009, also in the Bay of Naples. The estimated age of of these octopuses ranged from about 70 to $370 \mathrm{~d}$. Specimens with similar body weights had different numbers of rings, confirming the view that body size is a not a good index of age. Additionally, the relationship between body weight and number of rings was affected by sex and season, with the distance between rings clearly correlated to seasonal temperature oscillations. Our data suggest that different cohorts of octopus exist in the Bay of Naples and that temperature has a strong influence on growth. Overall the results demonstrate that growth increments in the upper beak of $O$. vulgaris provide a reliable method of aging that can be applied to assessing differences in the growth patterns in wild populations, and one that provides a record of environmental influences upon an individual.
\end{abstract}

KEY WORDS: Octopus $\cdot$ Age $\cdot$ Thermal marking $\cdot$ Upper beak $\cdot$ Seasonal variability Resale or republication not permitted without written consent of the publisher

\section{INTRODUCTION}

The cephalopod mollusc Octopus vulgaris Cuvier 1797 is an opportunistic benthic predator which has been reported from the Mediterranean, Atlantic, Pacific and Indian Oceans (Guerra et al. 2010). This species is considered to have, as a species complex, an almost worldwide distribution (Mangold 1997, Warnke et al. 2004). According to Norman (2000) 3 forms of $O$. vulgaris should be added to the original Mediterranean species: Caribbean, South African and Japanese common octopuses. O. vulgaris is one of the most important target species for commercial fisheries worldwide, with annual catches that exceed $40000 \mathrm{t} \mathrm{yr}^{-1}$ (FAO 2009).

Age determination is critical to understanding the life history of harvested species and for modelling their population dynamics. Growth increments (rings) recorded in hard structures (e.g. otoliths and scales in fish, statoliths in cephalopods) are a useful and reliable method for estimating the individual age in some taxa. Age and growth data can help in modelling appropriate management strategies in order to reduce fishery effects. 
Age determination in cephalopods has been based on both indirect and direct methods. Indirect methods are not reliable with cephalopods (e.g. Semmens et al. 2004), mainly because growth in any cephalopod species appears to be affected by a series of both biotic and abiotic factors, leading to large individual variability (Mangold 1983, Forsythe \& Van Heukelem 1987, Domain et al. 2000, Belcari et al. 2002). As a consequence, body size (weight and dorsal mantle length) is not a reliable indicator of age. For this reason indirect methods require validation by at least one direct method (Krstuloviç Šifner 2008).

Among direct methods, one of the most useful means of age estimation in cephalopods is statolith increment analysis. This method has been systematically applied to squids (Arkhipkin \& Laptikhovsky 1994, Jackson 1994, Rocha \& Guerra 1999, Arkhipkin 2005, Ikeda \& Kobayashi 2010) and to cuttlefish (Raya et al. 1994, Bettencourt \& Guerra 2001, Challier et al. 2002). Unfortunately, statolith analysis is not useful here as octopus species, including Octopus vulgaris, lack growth rings in this structure (Young 1960, Lombarte et al. 2006). In the case of O. vulgaris, other internal structures have been analysed over the past 20 yr for direct age determination. These include beaks and radulae (Nixon 1969, Raya \& HernándezGonzález 1998, Hernández-López et al. 2001), eye lenses (Gonçalves 1993 as cited in Hernández-López et al. 2001) and stylets (Reis \& Fernandes 2002, Hermosilla et al. 2010).

Validated and standardized methods of age determination for Octopus vulgaris using hard structures have not been identified (but see Hermosilla et al. 2010, Perales-Raya et al. 2010). Without an accurate age determination, parameters such as population structure, reproductive success, mortality rate, longevity, productivity and recruitment processes rely on assumptions derived only from morphometry and catch data (Leporati et al. 2008). The use of such potentially inaccurate methods may have disastrous consequences for the sustainability of octopus fisheries (Doubleday et al. 2006). Recently, Hermosilla et al. (2010) validated daily increments in the stylets of $O$. vulgaris. The investigators injected tetracycline and oxytetracycline, both of which form chelates with calcium, one of the major components of the structure (Napoleao et al. 2005). This resulted in a 'mark' visible by fluorescence, permitting correlation of number of growth increments with a known number of days between date of treatment and date of an animal's sacrifice (Hermosilla et al. 2010). Lipofuscin concentration has also been correlated to age in O. pallidus (Doubleday \& Semmens 2011).
Using specimens collected in the Bay of Naples, Italy (western Mediterranean Sea) during 2009 and 2010, we tested the hypothesis of daily periodicity of growth increments (rings) in the upper beak using 'thermal shock marking', correlating the number of rings formed with the number of days between the marking event and sacrifice. We also analysed growth increments in the upper beaks of Octopus vulgaris specimens that had been collected between 2003 and 2009, also in the Bay of Naples. In addition, we investigated whether beak ring density is affected by seasonal variations in seawater temperature, as suggested by Hernández-López et al. (2001).

\section{MATERIALS AND METHODS}

\section{Validation of age estimation by thermal marking}

We collected 56 octopuses (25 males and 31 females), with body weight (BW) ranging from 160 to $610 \mathrm{~g}$, in the Bay of Naples between October 2009 and March 2010. After capture, all octopuses were acclimatized to captivity in tanks $(30 \times 100 \times 60 \mathrm{~cm}$; water depth $45 \mathrm{~cm}$ ) supplied with circulating seawater for at least $14 \mathrm{~d}$. They were fed every second day with live crabs Carcinus mediterraneus. Following this acclimatization period, they were subjected to a thermal marking procedure following a technique similar to that used for fishes (Volk et al. 1999).

Forty-six acclimatized specimens were rapidly immersed in a bucket of seawater at $4^{\circ} \mathrm{C}$ and held there for $5 \mathrm{~min}$. This procedure constituted the 'thermal shock marking' (TSM). For a 10 min recovery period, specimens then were placed in a small bowl containing seawater at $24^{\circ} \mathrm{C}$. During this recovery period, the seawater was stirred to increase oxygenation. After the recovery period the octopuses were returned to the acclimatization tank. As a control, 10 individuals were immersed for $5 \mathrm{~min}$ in seawater at the same temperature as the acclimatization tank instead of $4^{\circ} \mathrm{C}$ (sham marking). Three runs were carried out using the same specimens: in October 2009 acclimatization seawater was at $21^{\circ} \mathrm{C}$; in December 2009 it was at $17^{\circ} \mathrm{C}$; and in March 2010 it was again at $21^{\circ} \mathrm{C}$. After TSM, octopuses were maintained for 29 to $34 \mathrm{~d}$. During this time they were fed every second day with crabs. At the end of the experiment all individuals were sacrificed using terminal anaesthesia (Grimaldi et al. 2007). Beaks were collected as described in the next paragraph. 


\section{Sampling of beaks and counting of increments}

A total of 735 buccal masses was collected between January 2003 and December 2009 from specimens that had been sacrificed during that period and dissected for other purposes. For each specimen the following body measurements were available: total BW in $\mathrm{g}$, and dorsal mantle length (DML) in mm. Sex was assessed following Chapko (1962; but see also Mangold 1983). Buccal masses were preserved in $70 \%$ ethanol or frozen $\left(-20^{\circ} \mathrm{C}\right)$

We followed the procedure of Hernández-López et al. (2001) for beak preparation. In brief, muscles and other tissues were removed from buccal masses by forceps, and beaks were cleaned by repeated washes in $10 \% \mathrm{H}_{2} \mathrm{O}_{2}$ and by brief immersion in $1 \mathrm{~N}$ $\mathrm{HCl}$ solution. After cleaning, and to facilitate examination, upper and lower beaks were flattened between 2 glass slides $(75 \times 51 \mathrm{~mm})$ which were held together by adhesive tape, thus maintaining pressure. Beaks were stored in transparent plastic folders and labelled to allow tracing of the individual octopus.

Rings were identified and counted under a Leica MZ16A binocular microscope; increments were clearly visible under epi-illumination. One of the 2 halves of each upper beak was chosen to count the growth increments. We proceeded along the dorsal axis from the posterior edge to the rostral tip (sensu Hernández-López et al. 2001; see also Perales-Raya et al. 2010).

\section{Precision in counting increments}

In agreement with Perales-Raya et al. (2010) precision is defined as the reproducibility of measurements of the examined structures (i.e. the rings). For this work, 2 trained readers made independent counts on the same sub-sample of 40 beaks. We then correlated the number of rings identified on each beak by the 2 readers using Pearson's correlation.

\section{Individual variability of increments at different seawater temperatures}

To evaluate possible differences in the pattern of ring deposition at various temperatures (HernándezLópez et al. 2001), a subsample of 93 beaks was selected from the whole set of 735 specimens according to the following criteria: (1) animals caught in either hot (June, July, August; about $26^{\circ} \mathrm{C}$ ) or cold
(December, January, February; about $15^{\circ} \mathrm{C}$ ) seasons; (2) individuals of a similar range of BW (from 200 to $500 \mathrm{~g}$ ); and (3) octopuses that had been maintained in laboratory under standardized and controlled conditions for < 2 wk (Fiorito et al. 1990). We estimated the linear distance in $\mathrm{mm}$ between the posterior edge and the 40th clearly identifiable ring. Mean interring width and increment density were determined in beaks between the edge and this 40th ring. We assumed that these increments were formed during a known climate period, i.e. the last $40 \mathrm{~d}$ before beak sampling. Increment counts were carried out as described in 'Sampling of beaks and counting of increments'.

\section{Data analysis and bioethical requirements}

Normal distribution and homogeneity of variances were assessed following Zar (1999). Simple linear correlation was utilized to test reliability of different readers in counting the number of rings. Chi-square goodness of fit was applied to thermal marking data. Correlation and curve-estimation were applied to describe the relationship between the variables considered and growth increments. Finally, a 2-sample $t$ test was employed to test differences in density of rings in samples collected in different seasons. All tests were 2-tailed, with alpha set at 0.05. Statistical analyses were performed using SPSS Statistics for Windows 18.0 (IBM).

Procedures for the maintenance, experimentation and sacrifice of Octopus vulgaris were carried out according to the current EU regulation for scientific use of living animals and following the national bioethical rules of Italy.

\section{RESULTS}

\section{Precision in counting of increments}

The 2 readers were consistent in evaluating the number of increments in the upper beaks examined $(\mathrm{r}=0.85 ; \mathrm{n}=40 ; \mathrm{p}<0.001)$.

\section{Validation of age estimation: thermal marking experiments}

No signs of marked stress reactions such as inking or thrashing were observed during thermal marking sessions. 

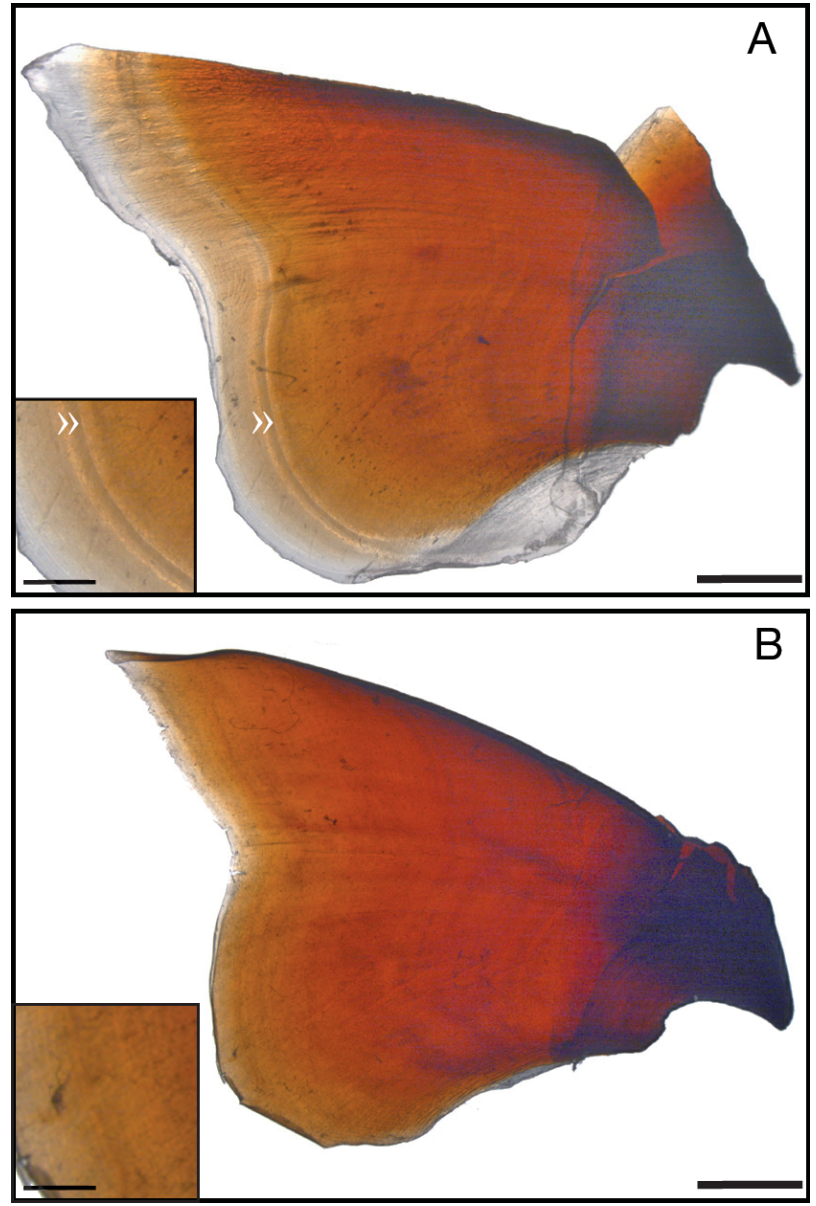

Fig. 1. Octopus vulgaris. Left half of upper beak (A) after thermal marking treatment, and (B) from control. Scale bar = $2 \mathrm{~mm}$. In (A) a bleached band is evident extending along the entire lateral wall (arrows). In (B) no bleaching is seen. Insets show detail of corresponding areas at higher magnification (scale bar $=0.9 \mathrm{~mm}$ ). Beak is oriented dorsal side up, with rostral tip to right. Crack in hood is artifact from sample preparation

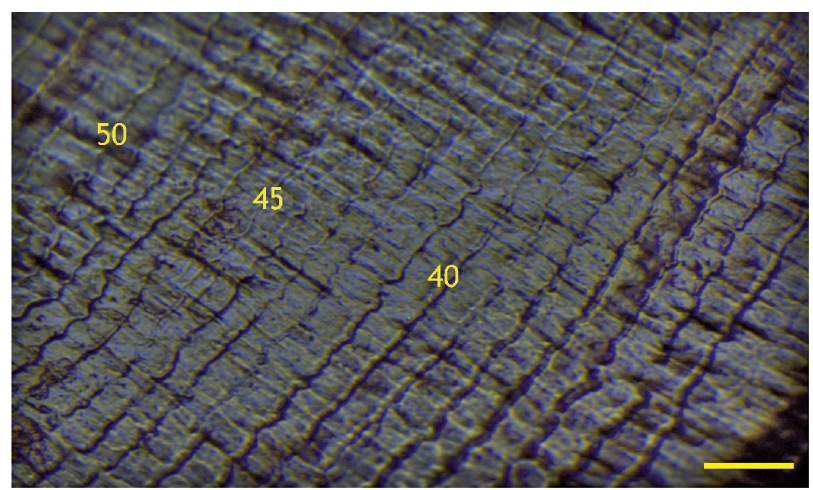

Fig. 2. Octopus vulgaris. Growth increments on the inner surface of lateral wall of octopus upper beak. Numbers indicate the counts of rings from the posterior edge. Scale bar $=150 \mu \mathrm{m}$
TSM produced a distinctive mark: a single dark ring in the midst of a bleached band (Fig. 1A). This was observed in $85 \%$ of the treated specimens (39 out of 46 ; chi-square $=22.3, \mathrm{df}=1, \mathrm{p}<0.001$ ). In the 39 marked beaks the number of growth increments counted between the posterior edge and the darker ring corresponded to an elapsed time of about a month (mean no. of days \pm SEM: $32.0 \pm 1.5$ ) from the thermal shock to the day of sacrifice. We detected no dark ring in beaks collected from octopuses that were not exposed to a thermal shock (sham marking; Fig. 1B). However, a partial mark, limited to only a part of the lateral wall and corresponding to a ring, was detected in 2 out of 10 specimens (chi-square = $3.6, \mathrm{df}=1, \mathrm{p}=0.058$ ).

\section{Increments in the upper beak}

The internal surfaces of the lateral wall of upper beaks revealed a clearly visible pattern of growth increments (Fig. 2), easily detectable along the axis chosen for counting. Rings were identified and counted on all 735 beaks of Octopus vulgaris (375 males, 360 females). As summarized in Table 1, rings ranged from a minimum of 72 to a maximum of 371 , belonging to 2 females of 200 and $2080 \mathrm{~g} \mathrm{BW}$, respectively (DML $=89.4$ and $223.3 \mathrm{~mm}$, respectively). It was not the youngest specimen that showed the lowest BW. For a female with the lowest BW $(58 \mathrm{~g})$, we counted 114 rings.

The best regression (cubic model) was obtained by plotting BW versus number of rings $\left(y=78.8+5.2 x^{3}-\right.$ $\left.0.03 x^{2}+6.9^{-5} x_{i} \mathrm{r}^{2}=0.33, F_{3731}=117.48, \mathrm{p}<0.001\right)$. Fig. 3 shows the relationship between BW and number of increments counted in the upper beaks by sex and season of capture. Regression for octupuses caught during winter resulted in lower coefficients (Fig. 3). Furthermore, females sampled during summer showed higher inter-individual variability than males (Fig. 3). Again, a greater variability emerged by comparing BW and rings for males: those collected during winter showed very low correlation coefficients when compared with those collected during summer $(r=0.382$ and 0.739 , respectively).

\section{Is individual variability due to seawater temperature?}

Among the 93 animals considered as subsample for this part of our study, the distance measured between the posterior edge of the beak and the 40th ring was 

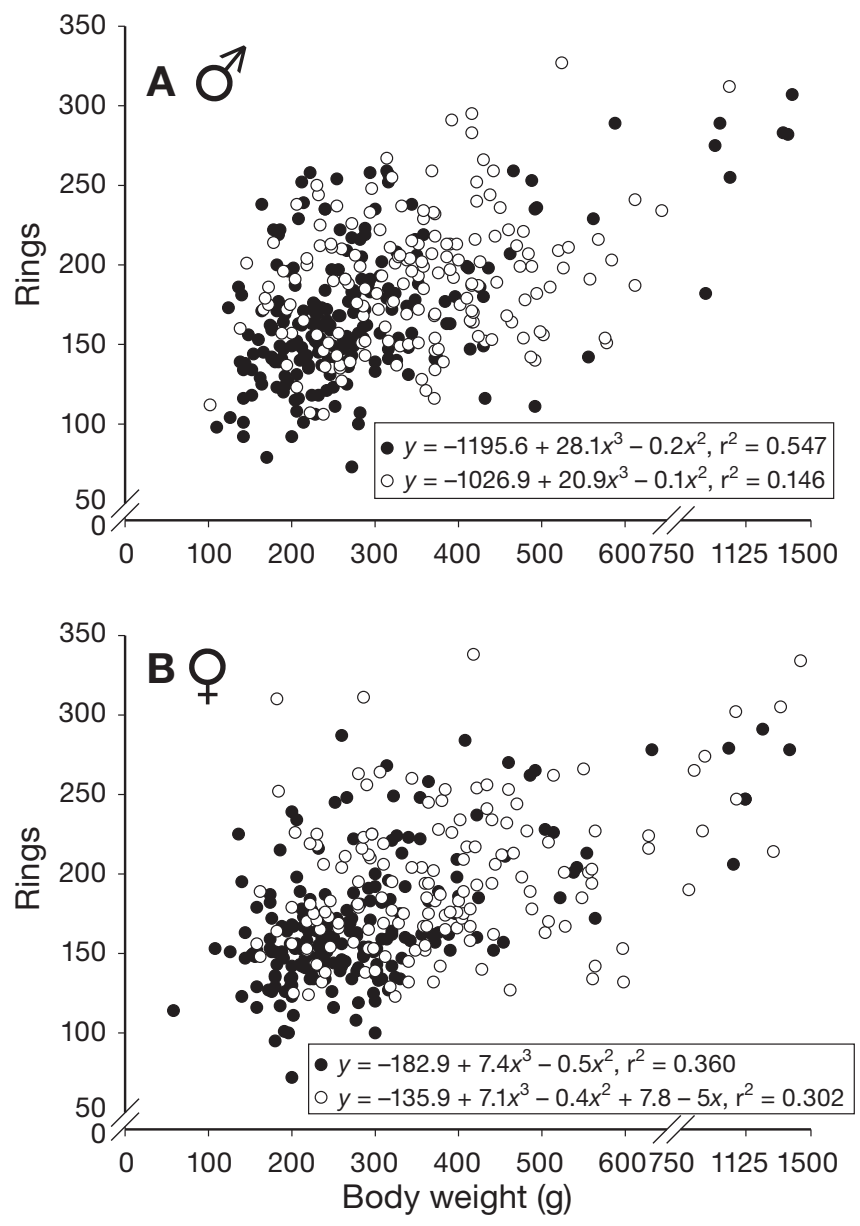

Fig. 3. Octopus vulgaris. Relationship between body weight and number of rings for males (A) and females (B) caught in summer (O) and winter (O); see text for details. Equations and $\mathrm{r}^{2}$ values after regression (cubic model) obtained from plotting body weight against number of rings for each season

longer in samples taken from the octopuses collected during summer than in those collected in winter $($ mean $\pm \mathrm{SEM}=3.3 \pm 0.1$ and $2.9 \pm 0.1 \mathrm{~mm}$, respectively). Consequently, mean widths for each increment counted along the main axis were smaller in beaks sampled from octopuses collected during winter than from those collected during summer (number of increments $\mathrm{mm}^{-1}$, mean density \pm SEM): summer $=10.6 \pm 0.4$, winter $=13.7 \pm 0.4 ; \mathrm{t}=5.8, \mathrm{df}=91$, $\mathrm{p}<0.001)$.

\section{DISCUSSION AND CONCLUSIONS}

\section{Validation of age estimation}

Our results provide, for the first time, experimental evidence of a daily deposition of growth increments in the upper beak of adult Octopus vulgaris. This confirms the one-day-one-increment hypothesis of Raya \& Hernández-González (1998), and the strict correspondence between the number of rings in beaks and days of life for octopus paralarvae (HernándezLópez et al. 2001). In addition, our results parallel those found in the vestigial shell of $O$. vulgaris by Hermosilla et al. (2010) and of O. pallidus by Doubleday et al. (2006). Beak increment analysis may thus provide alternative or additional data for age estimation in octopuses that may be of special value in cases where mantles are damaged.

Thermal shock marking, consisting of a sudden and short immersion of individuals in low-temperature water, has been applied here for the first time to cephalopods. It allowed us to identify a single distinctive dark ring, surrounded by a bleached area, corresponding to the day of treatment. The intensity and extent of the induced ring varied among individuals. In most cases the dark band corresponded to a ring extending along the entire lateral wall (dorsal to ventral). We recognized the band at approximately the 30th ring from the posterior margin. In some cases, the band was visible only on 1 of the 2 sides. Finally, in a few instances, only a short mark was recognized, but in the same position (30th ring). In only $15 \%$ of the octopuses that underwent a marking procedure we were unable to recognize any mark. Similar to what has been reported for fish otoliths, mark detection is not error-free (Volk et al. 1999). Errors may arise from poorly defined marks, difficulty of discrimination of the mark from the background increment pattern, poor sample preparation or defective samples. Both fish otoliths and octopus beaks are complex structures but similar in the alternation of clear and dark bands (rings). Otoliths are composed of both organic and inorganic components, the characteristic dark bands reflecting an organically rich component and the light bands a calcium-rich component. Octopus beaks, on the other hand, are composed mainly of chitin fibers $(\sim 20 \%)$ and proteins ( $45 \%$; Miserez et al. 2007). Thus, like fish otoliths, beaks are constituted mainly of matrices whose growth is governed by a biological rhythm (Wells et al. 1983, Raya \& Hernández-González 1998) depending on metabolic activity (Houlihan et al. 1990), and influenced by environmental conditions (e.g. temperature, stress; Volk et al. 1999, Campana 2005). A sudden drop in temperature might cause a metabolic shock, possibly inducing impairment of protein synthesis.

We cannot exclude the possibility that the extreme variability of the background ring pattern may have 


\begin{tabular}{|c|c|c|c|c|c|c|c|c|c|c|c|}
\hline 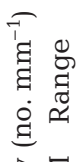 & 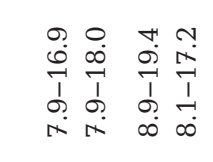 & 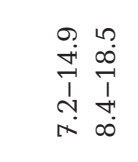 & 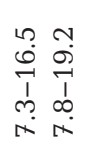 & $\begin{array}{ll}n & 0 \\
0 & 0 \\
9 & 0 \\
1 & 1 \\
\rightarrow & 1 \\
\infty & \infty\end{array}$ & 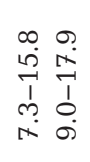 & $\begin{array}{ll}\infty & m \\
\infty & 0 \\
0 & 0 \\
1 & 1 \\
m & 1 \\
\infty & \infty\end{array}$ & 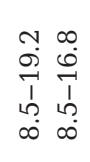 & 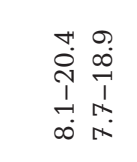 & $\begin{array}{ll}\overrightarrow{1} & 0 \\
\infty & 0 \\
\rightarrow & 0 \\
1 & 1 \\
0 & 0 \\
0 & 0\end{array}$ & 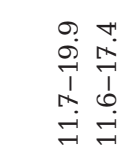 & 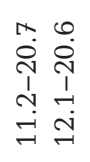 \\
\hline 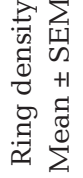 & 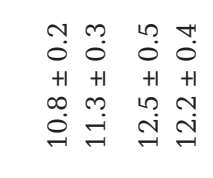 & 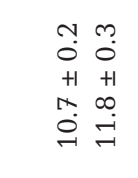 & 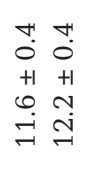 & 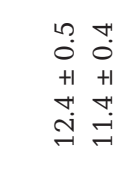 & 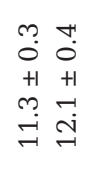 & 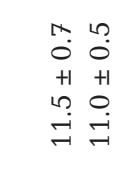 & 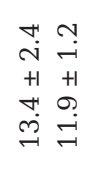 & $\begin{array}{ll}0 & 0 \\
0 & 0 \\
+1 & +1 \\
+1 & 0 \\
\ddot{M} & \stackrel{-}{\rightarrow} \\
\rightarrow & =\end{array}$ & 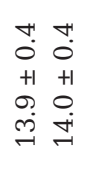 & 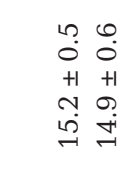 & 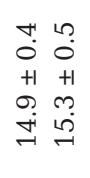 \\
\hline 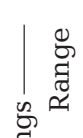 & 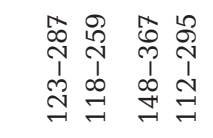 & 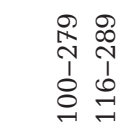 & 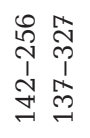 & 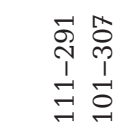 & 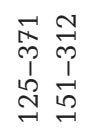 & 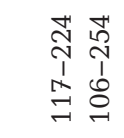 & 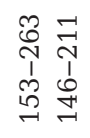 & 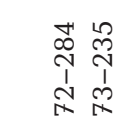 & 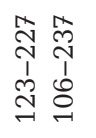 & 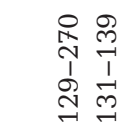 & 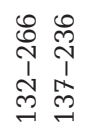 \\
\hline 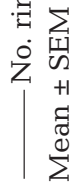 & 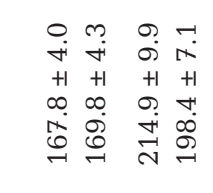 & 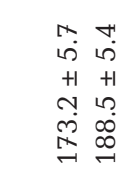 & 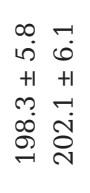 & 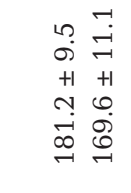 & 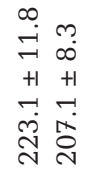 & 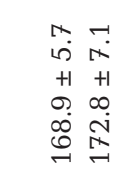 & 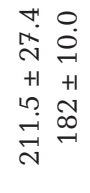 & 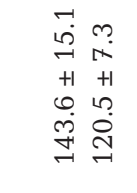 & $\begin{array}{ll}n & 0 \\
0 & 0 \\
0 & i n \\
+1 & +1 \\
0 & 0 \\
0 & 0 \\
0 & 0 \\
0 & 0\end{array}$ & $\begin{array}{ll}0 & \infty \\
0 & 0 \\
+1 & 1 \\
+1 & +1 \\
0 & 0 \\
\infty & 0 \\
0 & 0 \\
- & 0\end{array}$ & 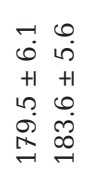 \\
\hline 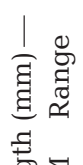 & 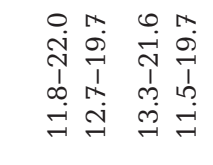 & 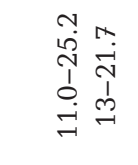 & 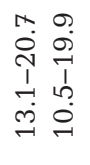 & 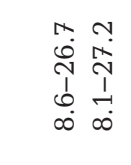 & 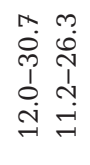 & 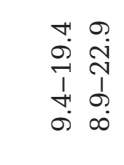 & 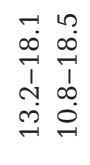 & 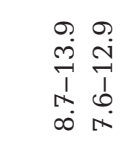 & $\begin{array}{ll}\infty & \infty \\
\dot{\omega} & \dot{9} \\
\overrightarrow{1} & \overrightarrow{1} \\
\vec{\sigma} & \stackrel{\vec{\sigma}}{\sigma}\end{array}$ & 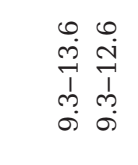 & $\begin{array}{ll}\infty & -1 \\
0 & -1 \\
\rightarrow & 0 \\
1 & \overrightarrow{1} \\
-1 & 1 \\
0 & 0 \\
- & \infty\end{array}$ \\
\hline 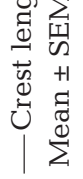 & 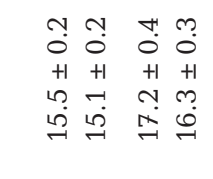 & $\begin{array}{ll}m & 1 \\
0 & 0 \\
+1 & +1 \\
\rightarrow-1 & 0 \\
0 & 0 \\
-1 & 0\end{array}$ & 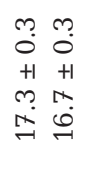 & 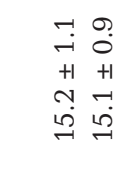 & $\begin{array}{ll}\infty & 0 \\
0 & 0 \\
+1 & +1 \\
+1 & 0 \\
0 & 0 \\
0 & 0\end{array}$ & $\begin{array}{ll}x & 0 \\
0 & 0 \\
+1 & +1 \\
0 & 0 \\
0 & 0 \\
& 0\end{array}$ & 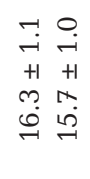 & 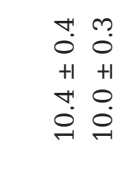 & 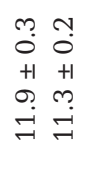 & 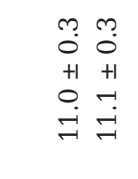 & 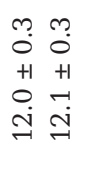 \\
\hline 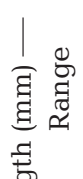 & 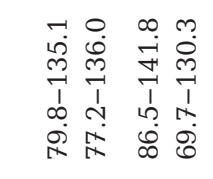 & 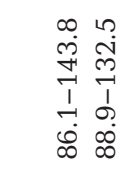 & 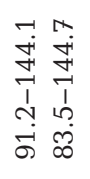 & 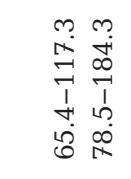 & 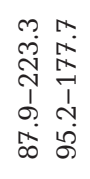 & 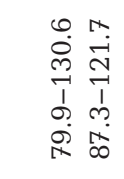 & 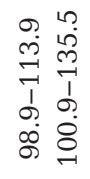 & 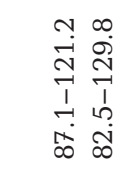 & 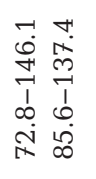 & 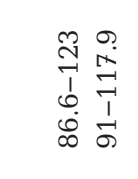 & 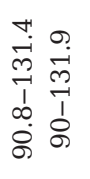 \\
\hline 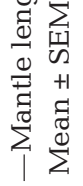 & 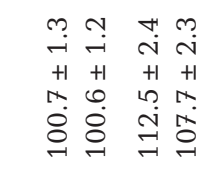 & 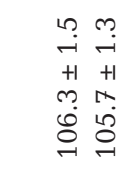 & 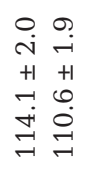 & 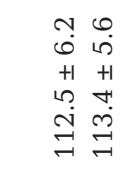 & 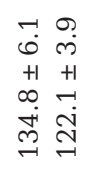 & 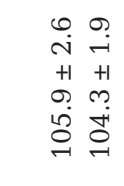 & 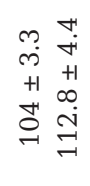 & 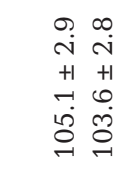 & 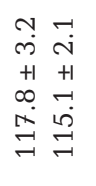 & 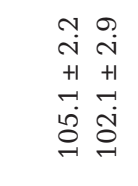 & 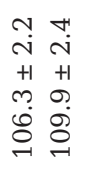 \\
\hline 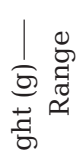 & 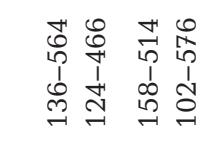 & 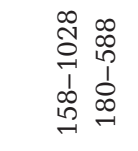 & 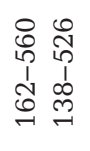 & 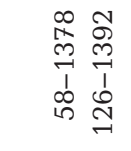 & 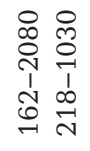 & 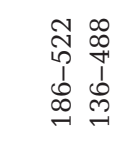 & 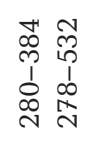 & 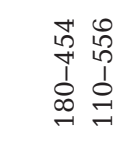 & 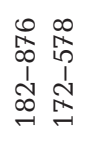 & $\begin{array}{ll}8 & 0 \\
0 & 9 \\
\dagger 1 & 7 \\
1 & 1 \\
0 & 0 \\
-1 & 0\end{array}$ & 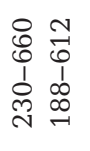 \\
\hline 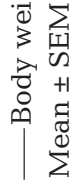 & 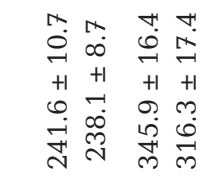 & 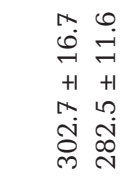 & 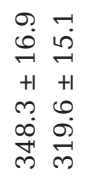 & 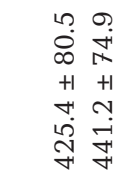 & 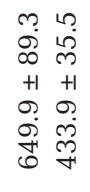 & 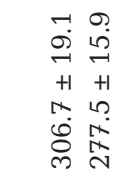 & 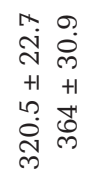 & 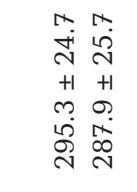 & 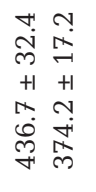 & 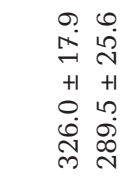 & 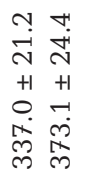 \\
\hline$\Rightarrow$ & 용 $\vec{m}$ & 8 in & Pे ঙ্+ & ฉి ః & $\stackrel{\sim}{\sim} \stackrel{\Re}{N}$ & $\stackrel{\overbrace{}}{\sim}$ & $r \alpha$ & $\underset{\exists}{~}$ & $\stackrel{\sim}{\sim}$ & $\stackrel{\infty}{\sim} \underset{\sim}{\sim}$ & $\stackrel{2}{2}$ \\
\hline 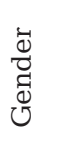 & 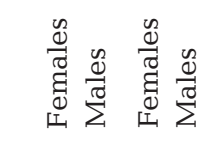 & 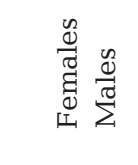 & 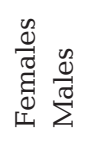 & 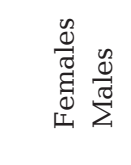 & 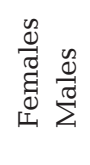 & 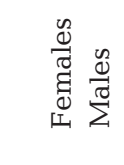 & 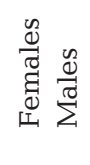 & 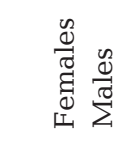 & 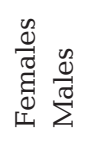 & 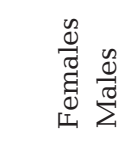 & 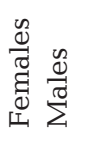 \\
\hline $\begin{array}{l}\tilde{0} \\
0 \\
0 \\
\mathbb{0} \\
n\end{array}$ & 范 & 苍苛 & 离 & ڤै & 离 & 节 & $\frac{\overrightarrow{0}}{\stackrel{5}{5}}$ & 离 & 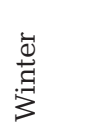 & 离 & 㟧 \\
\hline
\end{tabular}


interfered with the band resulting from the marking event, thus leading, at least in $15 \%$ of our samples, to our failure to discern a dark band in the beaks exposed to thermal shock. Similarly, we cannot exclude the possibility that marks recognized in controls ( 2 out of 10 cases) may have been due to stress or to a peculiar pattern of rings in the background not clearly distinguishable from a real mark. Daily formation of beak growth increments has been documented for octopus paralarvae (Hernández-López et al. 2001) and for certain adult size-classes (in this study), but this process needs to be documented for specimens of all sizes in order to validate the theory that daily formation of age increments extends throughout the entire life cycle of the species.

In a separate set of experiments (data not shown), we induced pharmacological inhibition of protein synthesis (using Cycloheximide) and of chitin synthesis (using Calcofluor White). Here, too, we obtained visible (in this case stained) increments, but the bleached areas were more extended. These results may correspond with an alteration of the internal structure (protein/chitin matrix) of the beak, thus confirming that growth of the beak is continuously supported by the metabolic and secretory activity of cells distributed along the entire surface of the beak (Dilly \& Nixon 1976, Wells et al. 1983, Houlihan et al. 1990).

\section{Increments in the upper beak and their variability}

In this work we determined the number of growth increments appearing in upper beaks sampled from a large number (735 individuals) of Octopus vulgaris specimens collected in the Bay of Naples. The collecting site was a well defined area covering $<10 \%$ of the gulf (the total area of which is $\sim 870 \mathrm{~km}^{2}$ ). Animals were sampled over $\sim 6 \mathrm{yr}$ and in different seasons. Concentric bands in all studied beaks were detectable, and, following a central counting axis (sensu Hernández-López et al. 2001; see also Perales-Raya et al. 2010), were counted along the internal surface of the upper beaks' lateral walls. Although this study was restricted to a particular range of BW (average $350 \mathrm{~g}$ ), the observed number of rings showed a quite remarkable range (between 72 and 371 increments). On the basis of assumed daily deposition, this suggests an estimated age of $\sim 2$ to 12 mo for the sampled specimens. Back-calculation to date of birth has allowed us to posit 2 spawning seasons in this region, as previously demonstrated by Guerra (1975).

Considering that - due to erosion of the rostral tip area during feeding (Perales-Raya et al. 2010) — the most distal rings should be difficult to discern, our age values may well be an underestimation. According to Perales-Raya et al. (2010), however, this may not significantly affect the measurements made in the distal region of the lateral wall area. Another possible source of bias may be the presence of 'false rings' along the lateral wall. False rings do not correspond to authentic growth increments because their formation may be influenced by environmental or metabolic conditions, independent of age. This may lead to overestimation of growth increments. Under the conditions of our experiment, the risk of considering a false ring as a true one is very limited; examination of the area along the lateral wall by our readers permitted easy identification and rejection of false rings, thus reducing the possibility of overestimation of age.

Previous studies have reported a positive correlation between number of increments in beaks and octopus body size, suggesting that increments are laid down regularly during individual growth (Raya \& Hernández-González 1998, Hernández-López et al. 2001, Perales-Raya et al. 2010). The observed variability within our sample, in terms of body size and age estimation (Table 1), confirms previous evidence that BW and DML are not reliable estimators of an octopus's age (Semmens et al. 2004). For example, individuals almost identical in age (e.g. with $\sim 150$ rings) were remarkably different in their body size (ranging from 100 to $600 \mathrm{~g}$; Fig. 3B). A similar view emerged from a recent study on Octopus vulgaris collected from central east Atlantic waters (see Table 1 of Perales-Raya et al. 2010). However, good regression values were obtained by plotting BW against number of rings (Fig. 3). Nevertheless, this relationship appears to be largely influenced by season (with accompanying temperature change) and sex (Table 1). In fact, we observed higher variability in octopuses collected during winter than in those collected during summer. Furthermore, of those collected during summer, females showed higher individual variability than males $\left(\mathrm{r}^{2}=0.360\right.$ versus 0.547 , respectively; Fig. 3), while males collected during winter had very low correlation coefficients in comparison to individuals caught in the summer $\left(\mathrm{r}^{2}=0.146\right.$ versus 0.547 , respectively; Fig. 3). Variability in body size among individuals and the poor correlation values observed suggest the presence of different cohorts in the Bay of Naples, similar to what has been reported for Atlantic and other Mediterranean sites (Guerra 1975, Belcari et al. 2002). When compared to octopuses caught off the Grand Canary (Hernández-López et al. 2001) our dataset shows a larger variability, despite its representing animals of a more limited range of body size. 
A series of biotic (e.g. age, size, sex, shape, food, activity, inter- and intra-specific interactions, populational and geographical effects) and abiotic factors (e.g. temperature, light, salinity, overall water quality) appear to affect cephalopod growth. Among them, temperature (whether due to latitudinal or seasonal effects), food availability and food quality have been considered most important. Even weekly temperature oscillations may have significant effects on the life history of cephalopods (Forsythe \& Hanlon 1988). Forsythe (1993) has suggested that individuals hatching during periods of higher seawater temperatures, as in late spring, produce cohorts that grow faster and become larger than those that hatched during periods of relatively lower temperatures (as in early spring). In extreme cases, cohorts of hatchlings born toward the end of spring might even surpass in size the cohorts hatched in early spring. In this sense, Rocha and Guerra (1999) showed that microcohorts of Loligo vulgaris and L. forbesi, identified according to estimated hatching date using statoliths, showed reduced individual variability and different growth curves, in apparent association with environmental variation. Future studies using beak growth rings as age estimators might use this type of analysis to reduce and understand the high individual variability observed in Octopus vulgaris. Several studies have provided strong evidence for the so-called 'Forsythe Effect' (Forsythe 1993) in a number of cephalopod species. (For review of these studies, see Forsythe 2004). As with other molluscan species, evidence is accumulating that cephalopods are good archives of the history of environmental change (e.g. Richardson 2001, Forsythe 2004, Arkhipkin 2005, Lazareth et al. 2006, Leporati et al. 2007, 2008).

Temperature effects were also evident when considering distance between rings on beaks of the individuals caught in different seasons. As has been reported for Loligo vulgaris paralarvae (Villanueva et al. 2003) and other molluscs (e.g. Pecten maximus, Owen et al. 2002), our data showed significant differences in ring density among individuals along the beak (data not shown). In addition, the density of rings appeared significantly different when samples from summer and winter were compared. Contrary to what has been suggested by Hernández-López et al. (2001) for Octopus vulgaris collected in the Atlantic Ocean, but in agreement with findings reported for $P$. maximus by Owen et al. (2002), we noted that the distance between 2 rings is greater during summer, while rings appear more densely packed in beaks from octopuses collected in winter. This is consistent with the higher growth rate observed in Mangold \&
Boletzky (1973) for this species at higher ambient temperatures, and in agreement with the Forsythe Hypothesis (Forsythe 1993).

In conclusion, our data support evidence of a daily increase in the number of rings in the upper beak of the cephalopod species Octopus vulgaris within the size range studied and provide evidence of a nondirect relationship between body size and individual age. Seasonal effects, possibly linked to seawater temperature, induce variability in the background pattern of growth increments and produce significant differences in density of rings along the beak. Thus, our data support the view that the octopus beak archives the history of environmental change, and perhaps the individual's life experience, as recognized for other structures in this taxon.

Acknowledgements. The authors thank V. Petrella and P. Coppola for help with sampling. Thanks also to P. Andrews for useful comments on the manuscript, and to anonymous reviewers for providing helpful comments and corrections.

\section{LITERATURE CITED}

Arkhipkin AI (2005) Statoliths as 'black boxes' (life recorders) in squid. Mar Freshw Res 56:573-583

Arkhipkin A, Laptikhovsky V (1994) Seasonal and interannual variability in growth and maturation of winterspawning Illex argentinus (Cephalopoda, Ommastrephidae) in the Southwest Atlantic. Aquat Living Resour 7: 221-232

Belcari P, Cuccu D, Gonzalez M, Srairi A, Vidoris P (2002) Distribution and abundance of Octopus vulgaris Cuvier, 1797 (Cephalopoda: Octopoda) in the Mediterranean sea. Sci Mar 66:157-166

$>$ Bettencourt V, Guerra A (2001) Age studies based on daily growth increments in statoliths and growth lamellae in cuttlebone of cultured Sepia officinalis. Mar Biol 139: 327-334

> Campana SE (2005) Otolith science entering the 21st century. Mar Freshw Res 56:485-495

> Challier L, Royer J, Robin JP (2002) Variability in age-atrecruitment and early growth in English Channel Sepia officinalis described with statolith analysis. Aquat Living Resour 15:303-311

Chapko MK (1962) Devilfish: a practical guide to the dissection of Octopus. Rocco Press, Wayne, NJ

Dilly PN, Nixon M (1976) The cells that secrete the beaks in octopods and squids (Mollusca, Cephalopoda). Cell Tissue Res 167:229-241

> Domain F, Jouffre D, Caverivere A (2000) Growth of Octopus vulgaris from tagging in Senegalese waters. J Mar Biol Assoc UK 80:699-705

> Doubleday ZA, Semmens JM (2011) Quantification of the age-pigment lipofuscin in known-age octopus (Octopus pallidus): a potential tool for age determination. J Exp Mar Biol Ecol 397:8-12

Doubleday Z, Semmens JM, Pecl G, Jackson G (2006) Assessing the validity of stylets as ageing tools in Octopus pallidus. J Exp Mar Biol Ecol 338:35-42 
FAO (Food and Agriculture Organization) (2009) Species fact sheets: Octopus vulgaris (Lamarck, 1798). Food and Agriculture Organization, Rome

Fiorito G, Von Planta C, Scotto P (1990) Problem solving ability of Octopus vulgaris Lamarck (Mollusca, Cephalopoda). Behav Neural Biol 53:217-230

Forsythe JW (1993) A working hypothesis of how seasonal temperature change may impact the field growth of young cephalopods. In: Okutani T, O'Dor RK, Kubodera $\mathrm{T}$ (eds) Recent advances in cephalopod fisheries biology. Tokai University Press, Tokyo, p 133-143

Forsythe JW (2004) Accounting for the effect of temperature on squid growth in nature: from hypothesis to practice. Mar Freshw Res 55:331-339

Forsythe JW, Hanlon RT (1988) Effect of temperature on laboratory growth, reproduction and life span of Octopus bimaculoides. Mar Biol 98:369-379

Forsythe JW, Van Heukelem WF (1987) Growth. In: Boyle PR (ed) Cephalopod life cycles, Vol 2: comparative reviews. Academic Press, London, p 135-155

Grimaldi AM, Agnisola C, Fiorito G (2007) Using ultrasound to estimate brain size in the cephalopod Octopus vulgaris Cuvier in vivo. Brain Res 1183:66-73

Guerra A (1975) Determinación de las diferentes fases del desarrollo sexual de Octopus vulgaris Lamarck, mediante un índice de madurez. Invest Pesq 39:397-416

Guerra A, Roura A, Gonzalez AF, Pascual S, Cherel Y, PerezLosada M (2010) Morphological and genetic evidence that Octopus vulgaris Cuvier, 1797 inhabits Amsterdam and Saint Paul Islands (southern Indian Ocean). ICES J Mar Sci 67:1401-1407

Hermosilla CA, Rocha F, Fiorito G, Gonzalez AF, Guerra A (2010) Age validation in common octopus Octopus vulgaris using stylet increment analysis. ICES J Mar Sci 67: 1458-1463

Hernández-López JL, Castro-Hernández JJ, HernándezGarcía V (2001) Age determined from the daily deposition of concentric rings on common octopus (Octopus vulgaris) beaks. Fish Bull 99:679-684

Houlihan DF, McMillan DN, Agnisola C, Genoino IT, Foti L (1990) Protein synthesis and growth in Octopus vulgaris. Mar Biol 106:251-259

> Ikeda Y, Kobayashi M (2010) Statolith growth of juvenile oval squid Sepioteuthis lessoniana (Cephalopoda: Loliginidae) with special reference to ambient thermal condition. Mar Biol Res 6:485-495

Jackson GD (1994) Application and future potential of statolith increment analysis in squids and sepioids. Can J Fish Aquat Sci 51:2612-2625

Krstuloviç Šifner S (2008) Methods for age and growth determination in cephalopods. Croat J Fish 66:25-34

> Lazareth CE, Lasne G, Ortlieb L (2006) Growth anomalies in Protothaca thaca (Mollusca, Veneridae) shells as markers of ENSO conditions. Clim Res 30:263-269

Leporati SC, Peel GT, Semmens JM (2007) Cephalopod hatchling growth: the effects of initial size and seasonal temperatures. Mar Biol 151:1375-1383

Leporati SC, Semmens JM, Pecl GT (2008) Determining the age and growth of wild octopus using stylet increment analysis. Mar Ecol Prog Ser 367:213-222

Lombarte A, Rufino MM, Sánchez P (2006) Statolith identification of Mediterranean Octopodidae, Sepiidae, Loliginidae, Ommastrephidae and Enoploteuthidae based on warp analyses. J Mar Biol Assoc UK 86:767-771

Mangold K (1983) Octopus vulgaris. In: Boyle PR (ed) Cephalopod life cycles, Vol 1: species accounts. Academic Press, London, p 335-364
Mangold K (1997) Octopus vulgaris: review of the biology. In: Lang MA, Hochberg FG (eds) The fishery and market potential of octopus in California. Smithsonian Institution, Washington, DC, p 85-90

Mangold K, Boletzky SV (1973) New data on reproductive biology and growth of Octopus vulgaris. Mar Biol 19: $7-12$

Miserez A, Li YL, Waite JH, Zok F (2007) Jumbo squid beaks: inspiration for design of robust organic composites. Acta Biomater 3:139-149

> Napoleao P, Reis CS, Alves LC, Pinheiro T (2005) Morphologic characterisation and elemental distribution of Octopus vulgaris Cuvier, 1797 vestigial shell. Nucl Instrum Methods Phys Res B 231:345-349

Nixon M (1969) Growth of the beak and radula of Octopus vulgaris. J Zool 159:363-379

Norman MD (2000) Cephalopods: a world guide. Conch Books, Hackenheim

Owen R, Richardson C, Kennedy H (2002) The influence of shell growth rate on striae deposition in the scallop Pecten maximus. J Mar Biol Assoc UK 82:621-623

Perales-Raya C, Bartolomé A, García-Santamaría MT, Pascual-Alayón P, Almansa E (2010) Age estimation obtained from analysis of octopus (Octopus vulgaris Cuvier, 1797) beaks: improvements and comparisons. Fish Res 106:171-176

> Raya CP, Hernández-González CL (1998) Growth lines within the beak microstructure of the octopus Octopus vulgaris Cuvier, 1797. S Afr J Mar Sci 20:135-142

- Raya CP, Fernández-Núñez M, Balguerías E, HernándezGonzález CL (1994) Progress towards ageing cuttlefish Sepia hierredda from the northwestern African coast using statoliths. Mar Ecol Prog Ser 114:139-147

Reis CS, Fernandes R (2002) Growth observations on Octopus vulgaris Cuvier, 1797 from the Portuguese waters: growth lines in the vestigial shell as possible tools for age determination. Bull Mar Sci 71:1099-1103

Richardson CA (2001) Molluscs as archives of environmental change. Oceanogr Mar Biol 39:103-164

Rocha F, Guerra A (1999) Age and growth of two sympatric squid Loligo vulgaris and Loligo forbesi, in Galician waters (north-west Spain). J Mar Biol Assoc UK 79: $697-707$

Semmens JM, Pecl GT, Villanueva R, Jouffre D, Sobrino I, Wood JB, Rigby PR (2004) Understanding octopus growth: patterns, variability and physiology. Mar Freshw Res 55:367-377

Villanueva R, Arkhipkin A, Jereb P, Lefkaditou E and others (2003) Embryonic life of the loliginid squid Loligo vulgaris: comparison between statoliths of Atlantic and Mediterranean populations. Mar Ecol Prog Ser 253:197-208

Volk EC, Schroder SL, Grimm JJ (1999) Otolith thermal marking. Fish Res 43:205-219

Warnke K, Soller R, Blohm D, Saint-Paul U (2004) A new look at geographic and phylogenetic relationships within the species group surrounding Octopus vulgaris (Mollusca, Cephalopoda): indications of very wide distribution from mitochondrial DNA sequences. J Zoological Syst Evol Res 42:306-312

- Wells MJ, Odor RK, Mangold K, Wells J (1983) Diurnal changes in activity and metabolic-rate in Octopus vulgaris. Mar Behav Physiol 9:275-287

Young JZ (1960) The statocysts of Octopus vulgaris. Proc R Soc Lond Biol Sci 152:3-29

Zar JH (1999) Biostatistical analysis. Prentice Hall, Upper Saddle River, NJ 